\title{
Effects of Two Ecotypes Mutual Grafting on Nutrient Absorption of Post Generations of Solanum photeinocarpum under Cadmium Stress
}

\author{
Qian Zhang ${ }^{1, \mathrm{a}}$, Jianhua $\mathrm{Li}^{2, \mathrm{~b}}$, Huan Yao, ${ }^{1, \mathrm{c}}$, Zicheng Lü, ${ }^{3, \mathrm{~d}}$, Maolin $\mathrm{Chen}^{4, \mathrm{e}}$, \\ Mei Qing ${ }^{1, f}$ and Lijin Lin ${ }^{5,9 *}$ \\ ${ }^{1}$ College of Horticulture, Sichuan Agricultural University, Chengdu, Sichuan, China
}

${ }^{2}$ Sichuan Ya'an Municipal Product Quality Supervision \& Inspection Institute, Ya'an, Sichuan, China

${ }^{3}$ College of Agronomy, Sichuan Agricultural University, Chengdu, Sichuan, China

${ }^{4}$ College of Economics, Sichuan Agricultural University, Chengdu, Sichuan, China

${ }^{5}$ Institute of Pomology and Olericulture, Sichuan Agricultural University, Chengdu, Sichuan, China

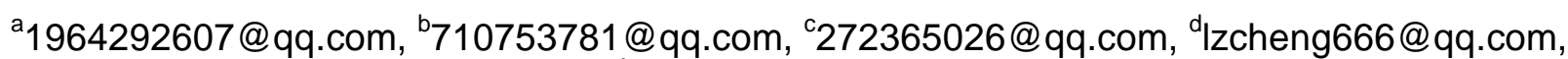
e3208585092@qq.com, ${ }^{\mathrm{f}} 1115435013 @ q q . c o m,{ }^{9}$ llj800924@163.com

${ }^{*}$ Corresponding author. Qian Zhang and Jianhua Li contributed equally to this work.

Keywords: Solanum photeinocarpum; Mutual grafting; Nutrient absorption; Post generation

Abstract: A pot experiment was carried out to study the effects of two ecotypes mutual grafting on nutrient absorption of post generations of Solanum photeinocarpum under cadmium stress. Two ecotypes mutual grafting increased the total $\mathrm{N}$, total $\mathrm{P}$ contents in roots, stems and leaves of post generations of $S$. photeinocarpum under Cd stress, which were benefit to the growth of $S$. photeinocarpum. However, mutual grafting had little effects on total $\mathrm{K}$ content in roots of post generations of S. photeinocarpum, and had no significant effects on total K content in stems and leaves of that. Mutual grafting increased the available $\mathrm{P}$ and available $\mathrm{K}$ concentrations, but had little effects on soil alkali soluble $\mathrm{N}$ concentration. Therefore, two ecotypes mutual grafting could promote the nutrient uptake of post generations of $S$. photeinocarpum under Cd stress.

\section{Introduction}

Solanum photeinocarpum is a potential cadmium (Cd) hyperaccumulator plant [1]. In the wild, because of different climate environment, the different ecotypes of $S$. photeinocarpum formed, such as the farmland ecotype, mining ecotype [2]. Compared with the other Cd-hyperaccumulator plants [3-4], the phytoremediation ability of $S$. photeinocarpum is low. So, to further enhancing the phytoremediation ability of $S$. photeinocarpum, a pot experiment was conducted to study the effects of mutual grafting on the nutrient absorption of two ecotypes of post generation $S$. photeinocarpum under Cd stress. The objectives of this study were to determine whether mutual grafting could enhance nutrient absorption ability of two ecotypes of post generation $S$. photeinocarpum under Cd stress, and provide a reference for other hyperaccumulator plants.

\section{Materials and Methods}

Materials. The seeds of two ecotypes (mining ecotype and farmland ecotype) of S. photeinocarpum were collected from Tangjiashan lead-zinc mine and farmland of Ya'an campus farm of Sichuan Agricultural University in May, 2016, air-dried and stored at $4{ }^{\circ} \mathrm{C}$ respectively. The Tangjiashan lead-zinc mine $\left(29^{\circ} 24^{\prime} \mathrm{N}, 102^{\circ} 38^{\prime} \mathrm{E}\right)$ locates in Hanyuan County, Sichuan Province, China, with an typical dry-hot valley climate. The farm of Sichuan Agricultural University (29 $\left.59^{\prime} \mathrm{N}, 102^{\circ} 59^{\prime} \mathrm{E}\right)$ locates in Yucheng County, Sichuan Province, China, with an humid subtropical monsoon climate.

Grafting. The seeds of two ecotypes of S. photeinocarpum were sown in the farmland of the Chengdu campus in June, 2016. When the $S$. photeinocarpum seedlings reached a height of $\sim 10 \mathrm{~cm}$ (eight expanded euphyllas, rapid growth stage), the grafting was conducted. The grafting method was 
cleft grafting bound with 1-cm-wide plastic film. All of the leaves of the rootstocks remained. There were four treatments in the experiment. (1) Un-grafted of farmland ecotype (FCK). (2) Un-grafted of mining ecotype (MCK). (3) The farmland ecotype as scion grafted on the rootstocks of mining ecotype (FSC). (4) The mining ecotype as scion grafted on the rootstocks of farmland ecotype (MSC). When the grafting was completed, the soil moisture content was maintained at $80 \%$ of field capacity, and all of the seedlings were covered with transparent plastic film and a shade net. After $10 \mathrm{~d}$, the transparent plastic film, the shade net and the plastic binding films were removed. At maturity (50 d after grafting), fruits of S. photeinocarpum from CK, scion and rootstock were collected, and the seeds were taken out from fruits, air-dried and stored separately at $4{ }^{\circ} \mathrm{C}$, which were recorded as un-grafted of farmland ecotype (FCK1), rootstock of farmland ecotype (FRT1), scion of farmland ecotype (FSC1), un-grafted of mining ecotype (MCK1), rootstock of mining ecotype (MRT1) and scion of mining ecotype (MSC1).

Experimental Design. The experiment was conducted at the Chengdu campus from April to July 2017. The soil samples were air-dried and passed through a 5-mm mesh in April 2017, and then $3.0 \mathrm{~kg}$ of soil was weighed into each polyethylene pot (15 cm tall, $18 \mathrm{~cm}$ diameter). Cd was added to make a final soil Cd concentration of $10 \mathrm{mg} / \mathrm{kg}$ [5] with a saturated heavy metal solution in the form of $\mathrm{CdCl}_{2} \cdot 2.5 \mathrm{H}_{2} \mathrm{O}$. The soils were mixed immediately and again after 8 weeks, during which soil moisture was kept at $80 \%$. The seeds of $S$. photeinocarpum were sown in the un-contaminated soil in May 2017. Four uniform $S$. photeinocarpum seedlings with four expanded true leaves of each treatment were transplanted into each pot in June 2017. Each treatment was repeated three times with the 10-cm spacing between pots. The soil moisture content was maintained at $80 \%$ of field capacity until the plants were harvested. After S. photeinocarpum matured (30 d of cultivation at the fully blooming stage), the whole plants were dug up and divided into three parts of root, stem, leaf, then washed with tap water firstly, followed by deionized water. After that, the organs of all plants were dried at $80{ }^{\circ} \mathrm{C}$ until constant weight, weighed, ground to $<0.149 \mathrm{~mm}$, and sealed into plastic bags for the determination of total nitrogen $(\mathrm{N})$, total phosphorus $(\mathrm{P})$ and total potassium $(\mathrm{K})$ contents [6]. The soil sample was collected, air-dried and ground to $<1.0 \mathrm{~mm}$ for analysis of alkali soluble $\mathrm{N}$, available $\mathrm{P}$ and available K concentrations [6].

Statistical Analyses. Statistical analyses were conducted using SPSS 13.0 statistical software (IBM, Chicago, IL, USA). Data were analyzed by one-way analysis of variance with least significant difference (LSD) at the $\mathrm{p}=0.05$ confidence level.

\section{Results and Discussion}

Total N Contents in Post Generations of S. photeinocarpum. The mutual grafting increased the total $\mathrm{N}$ contents in post generations of two ecotypes of $S$. photeinocarpum (Table 1). Compared with FCK1, FRT1 and FSC1 increased total N content in roots of $S$. photeinocarpum by $19.26 \%(p<0.05)$ and $22.13 \%(p<0.05)$, respectively, increased total $\mathrm{N}$ content in stems by $21.28 \%(p<0.05)$ and $26.60 \%(p<0.05)$, respectively, and increased total $\mathrm{N}$ content in leaves by $1.60 \%(p>0.05)$ and $6.91 \%$ ( $p<0.05)$, respectively. Compared with MCK1, MRT1 and MSC1 increased total N content in roots of S. photeinocarpum by $26.05 \%(p<0.05)$ and $9.58 \%(p<0.05)$, respectively, increased total N content in stems by $13.69 \%(p<0.05)$ and $12.03 \%(p<0.05)$, respectively, and increased total $\mathrm{N}$ content in leaves by $29.66 \%(p<0.05)$ and $11.02 \%(p<0.05)$, respectively.

Total P Contents in Post Generations of S. photeinocarpum. The mutual grafting increased the total $\mathrm{P}$ contents in post generations of two ecotypes of $S$. photeinocarpum (Table 2). Compared with FCK1, FRT1 and FSC1 increased total P content in roots of $S$. photeinocarpum by $21.32 \%(p<0.05)$ and $35.74 \%(p<0.05)$, respectively, increased total P content in stems by $13.33 \%(p<0.05)$ and $40.89 \%(p<0.05)$, respectively, and increased total P content in leaves by $3.73 \%(p>0.05)$ and $44.10 \%(p<0.05)$, respectively. Compared with MCK1, MRT1 and MSC1 increased total P content in roots of $S$. photeinocarpum by $34.15 \%(p<0.05)$ and $33.23 \%(p<0.05)$, respectively, increased total $\mathrm{P}$ content in stems by $33.50 \%(p<0.05)$ and $6.50 \%(p>0.05)$, respectively, and increased total $\mathrm{P}$ 
content in leaves by $38.06 \%(p<0.05)$ and $26.37 \%(p<0.05)$, respectively.

Table 1 Total N contents in post generations of S. photeinocarpum under Cd stress

\begin{tabular}{|c|c|c|c|}
\hline Treatments & $\begin{array}{c}\text { Roots } \\
(\mathrm{mg} / \mathrm{g})\end{array}$ & $\begin{array}{c}\text { Stems } \\
(\mathrm{mg} / \mathrm{g})\end{array}$ & $\begin{array}{c}\text { Leaves } \\
(\mathrm{mg} / \mathrm{g})\end{array}$ \\
\hline FCK1 & $2.44 \pm 0.06 \mathrm{c}$ & $1.88 \pm 0.06 \mathrm{c}$ & $3.76 \pm 0.10 \mathrm{bc}$ \\
\hline FRT1 & $2.91 \pm 0.11 \mathrm{~b}$ & $2.28 \pm 0.07 \mathrm{~b}$ & $3.82 \pm 0.13 \mathrm{bc}$ \\
\hline FSC1 & $2.98 \pm 0.08 \mathrm{~b}$ & $2.38 \pm 0.10 \mathrm{~b}$ & $4.02 \pm 0.14 \mathrm{~b}$ \\
\hline MCK1 & $2.61 \pm 0.10 \mathrm{c}$ & $2.41 \pm 0.13 \mathrm{~b}$ & $3.54 \pm 0.08 \mathrm{c}$ \\
\hline MRT1 & $3.29 \pm 0.14 \mathrm{a}$ & $2.74 \pm 0.07 \mathrm{a}$ & $4.59 \pm 0.13 \mathrm{a}$ \\
\hline MSC1 & $2.86 \pm 0.07 \mathrm{~b}$ & $2.70 \pm 0.11 \mathrm{a}$ & $3.93 \pm 0.11 \mathrm{~b}$ \\
\hline
\end{tabular}

Values are means \pm standard errors. Means with the same letter within each column are not significantly different at $p<0.05$.

Table 2 Total P contents in post generations of S. photeinocarpum under Cd stress

\begin{tabular}{|c|c|c|c|}
\hline Treatments & $\begin{array}{c}\text { Roots } \\
(\mathrm{mg} / \mathrm{g})\end{array}$ & $\begin{array}{c}\text { Stems } \\
(\mathrm{mg} / \mathrm{g})\end{array}$ & $\begin{array}{c}\text { Leaves } \\
(\mathrm{mg} / \mathrm{g})\end{array}$ \\
\hline FCK1 & $3.33 \pm 0.13 \mathrm{c}$ & $2.25 \pm 0.07 \mathrm{c}$ & $3.22 \pm 0.12 \mathrm{e}$ \\
\hline FRT1 & $4.04 \pm 0.04 \mathrm{~b}$ & $2.55 \pm 0.08 \mathrm{~b}$ & $3.34 \pm 0.05 \mathrm{e}$ \\
\hline FSC1 & $4.52 \pm 0.06 \mathrm{a}$ & $3.17 \pm 0.09 \mathrm{a}$ & $4.64 \pm 0.06 \mathrm{c}$ \\
\hline MCK1 & $3.25 \pm 0.02 \mathrm{c}$ & $2.00 \pm 0.05 \mathrm{~d}$ & $4.02 \pm 0.17 \mathrm{~d}$ \\
\hline MRT1 & $4.36 \pm 0.06 \mathrm{a}$ & $2.67 \pm 0.14 \mathrm{~b}$ & $5.55 \pm 0.07 \mathrm{a}$ \\
\hline MSC1 & $4.33 \pm 0.10 \mathrm{a}$ & $2.13 \pm 0.10 \mathrm{~cd}$ & $5.08 \pm 0.06 \mathrm{~b}$ \\
\hline
\end{tabular}

Values are means \pm standard errors. Means with the same letter within each column are not significantly different at $p<0.05$.

Total K Contents in Post Generations of S. photeinocarpum. The mutual grafting increased the total K contents in roots of post generations of $S$. photeinocarpum (Table 3). Compared with FCK1, FRT1 and FSC1 increased total K content in roots of $S$. photeinocarpum by $2.46 \%(p>0.05)$ and $13.18 \%(p<0.05)$, respectively. Compared with MCK1, MRT1 and MSC1 increased total K content in roots of $S$. photeinocarpum by $10.21 \%(p>0.05)$ and $2.21 \%(p>0.05)$, respectively. However, compared with the un-grafted $S$. photeinocarpum, the K contents in stems and leaves of post generations of mutual grafting $S$. photeinocarpum had no significant changes. So, mutual grafting had no obvious effects on K uptake in shoots of post generations of S. photeinocarpum.

Table 3 Total K contents in post generations of S. photeinocarpum under Cd stress

\begin{tabular}{|c|c|c|c|}
\hline Treatments & $\begin{array}{c}\text { Roots } \\
(\mathrm{mg} / \mathrm{g})\end{array}$ & $\begin{array}{c}\text { Stems } \\
(\mathrm{mg} / \mathrm{g})\end{array}$ & $\begin{array}{c}\text { Leaves } \\
(\mathrm{mg} / \mathrm{g})\end{array}$ \\
\hline FCK1 & $20.71 \pm 1.20 \mathrm{~b}$ & $16.86 \pm 0.21 \mathrm{a}$ & $23.47 \pm 1.20 \mathrm{a}$ \\
\hline FRT1 & $21.22 \pm 1.15 \mathrm{ab}$ & $18.20 \pm 1.58 \mathrm{a}$ & $24.11 \pm 1.26 \mathrm{a}$ \\
\hline FSC1 & $23.44 \pm 0.61 \mathrm{a}$ & $18.76 \pm 1.07 \mathrm{a}$ & $24.34 \pm 1.77 \mathrm{a}$ \\
\hline MCK1 & $20.86 \pm 1.19 \mathrm{~b}$ & $17.35 \pm 0.92 \mathrm{a}$ & $23.23 \pm 1.09 \mathrm{a}$ \\
\hline MRT1 & $22.99 \pm 0.89 \mathrm{ab}$ & $18.94 \pm 1.50 \mathrm{a}$ & $25.28 \pm 0.69 \mathrm{a}$ \\
\hline MSC1 & $21.32 \pm 0.34 \mathrm{ab}$ & $17.85 \pm 1.63 \mathrm{a}$ & $23.43 \pm 1.51 \mathrm{a}$ \\
\hline
\end{tabular}

Values are means \pm standard errors. Means with the same letter within each column are not significantly different at $p<0.05$.

Soil Alkali Soluble N, Available P and Available K Concentrations. Compared with FCK1, FRT1 and FSC1 increased soil alkali soluble N concentration by $7.04 \%(p>0.05)$ and $31.48 \%(p<$ $0.05)$, respectively, increased soil available $\mathrm{P}$ concentration by $2.08 \%(p>0.05)$ and $30.06 \%(p<$ 
$0.05)$, respectively, and increased soil available K concentration by $9.09 \%(p>0.05)$ and $45.16 \%(p<$ 0.05), respectively. Compared with MCK1, MRT1 and MSC1 increased soil alkali soluble $\mathrm{N}$ concentration by $7.47 \%(p>0.05)$ and $3.86 \%(p>0.05)$, respectively, increased soil available P concentration by $37.18 \%(p<0.05)$ and $18.46 \%(p<0.05)$, respectively, and increased soil available K concentration by $28.39 \%(p>0.05)$ and $14.27 \%(p<0.05)$, respectively.

Table 4 Soil alkali soluble $\mathrm{N}$, available $\mathrm{P}$ and available K concentrations

\begin{tabular}{|c|c|c|c|}
\hline Treatments & $\begin{array}{c}\text { Alkali soluble N } \\
(\mathrm{mg} / \mathrm{kg})\end{array}$ & $\begin{array}{c}\text { Available P } \\
(\mathrm{mg} / \mathrm{kg})\end{array}$ & $\begin{array}{c}\text { Available K } \\
(\mathrm{mg} / \mathrm{kg})\end{array}$ \\
\hline FCK1 & $74.58 \pm 2.18 \mathrm{~b}$ & $3.36 \pm 0.08 \mathrm{~d}$ & $102.53 \pm 4.71 \mathrm{~d}$ \\
\hline FRT1 & $79.83 \pm 4.84 \mathrm{~b}$ & $3.43 \pm 0.12 \mathrm{~d}$ & $111.85 \pm 6.32 \mathrm{~d}$ \\
\hline FSC1 & $98.06 \pm 5.88 \mathrm{a}$ & $4.37 \pm 0.14 \mathrm{~b}$ & $148.83 \pm 5.74 \mathrm{~b}$ \\
\hline MCK1 & $90.91 \pm 3.10 \mathrm{a}$ & $3.90 \pm 0.16 \mathrm{c}$ & $130.37 \pm 7.65 \mathrm{c}$ \\
\hline MRT1 & $97.70 \pm 2.63 \mathrm{a}$ & $5.35 \pm 0.06 \mathrm{a}$ & $167.38 \pm 6.52 \mathrm{a}$ \\
\hline MSC1 & $94.42 \pm 3.49 \mathrm{a}$ & $4.62 \pm 0.11 \mathrm{~b}$ & $148.98 \pm 4.43 \mathrm{~b}$ \\
\hline
\end{tabular}

Values are means \pm standard errors. Means with the same letter within each column are not significantly different at $p<0.05$.

\section{Conclusions}

Under Cd stress, two ecotypes mutual grafting increased the total $\mathrm{N}$, total $\mathrm{P}$ contents in roots, stems and leaves of post generations of $S$. photeinocarpum, which were benefit to the growth of $S$. photeinocarpum. However, mutual grafting had little effects on total $\mathrm{K}$ content in roots of post generations of $S$. photeinocarpum, and had no significant effects on total K content in stems and leaves of that. Mutual grafting increased the available $\mathrm{P}$ and available $\mathrm{K}$ concentrations, but had little effects on soil alkali soluble $\mathrm{N}$ concentration. Therefore, two ecotypes mutual grafting could promote the nutrient uptake of post generations of $S$. photeinocarpum under Cd stress.

\section{Acknowledgements}

This work was financially supported by the 2016 Innovation Training Program of University Student (201610626032) and the Application Infrastructure Project of Science and Technology Department of Sichuan Province (2016JY0258).

\section{References}

[1] X.F. Zhang, H.P. Xia, Z.A. Li, P. Zhuang and B. Gao: Journal of Hazardous Materials Vol. 189 (2011), p. 414.

[2] J. Wang, L. Jin, L. Luo, M. Liao, X. Lv, Z. Wang, D. Liang and H. Xia: Environmental Monitoring and Assessment Vol. 188 (2016), p. 82.

[3] X.X. Long, Y.H. Wang and H.Y. Liu: Journal of Plant Ecology Vol. 32 (2008), p. 168.

[4] S.H. Wei, G. Clark, A.I. Doronila, J. Jin and A.C. Monsant: International Journal of Phytoremediation Vol. 15 (2013), p. 199.

[5] L. Lin, M. Liao, L. Mei, J. Cheng, J. Liu, L. Luo and Y. Liu: Environmental Progress \& Sustainable Energy Vol. 33 (2014), p. 1251.

[6] S.D. Bao: Agrochemical Soil Analysis (3rd edition, China Agriculture Press, Beijing, China 2000). 